\title{
Del gobierno judicial colombiano bajo la constitución de 1886
}

\author{
Recibido: 4 de mayo de 2020 • Aprobado: 4 de junio de 2020 \\ https://doi.org/10.22395/ojum.v20n4lal1
}

\author{
Sergio Zapata Romero \\ Universidad Popular del Cesar, Valledupar, Colombia \\ sergiozapata@unicesar.edu.co \\ https://orcid.org/0000-0002-9107-734X
}

\section{RESUMEN}

El presente artículo corresponde a un avance del proyecto de investigación Autarquía judicial en Latinoamérica: antecedentes, alcances, logros y retos. Para el caso puntual, este artículo pretende identificar la forma en que se implementó el gobierno de lo judicial en el marco de la constitución de 1886, así como las razones que motivaron su establecimiento y evolución durante la vigencia de dicha carta política. Para lograr lo anterior se combinaron la investigación histórico-jurídica y socio-jurídica bajo un enfoque mixto (teórico-empírico) cuantitativo y hermenéutico, lo que permitió concluir la existencia de un sustrato autoritario en el gobierno judicial bajo la constitución regeneracionista. Este Gobierno impuso un nocivo control administrativo y de tutela del Poder Ejecutivo en los asuntos judiciales, sobre el cual se edificaría la resistencia de la estructura jurídica para acoger el tránsito hacia la autarquía judicial que se planteaba como una solución a los problemas que aquejaban a la administración de justicia.

Palabras clave: rama judicial; Fondo Rotatorio Judicial; Ministerio de Justicia; administración de lo judicial; autogobierno judicial; control administrativo y de tutela; Constitución de 1886. 


\title{
On the Colombian Judicial Government Under the Constitution of 1886
}

\begin{abstract}
This article corresponds to an advance of the research project "Judicial autarchy in Latin America: background, scope, achievements and challenges" which for the specific case aims to identify the way in which the judicial government was implemented within the framework of the 1886 constitution; as well as the reasons that motivated its establishment and evolution during the validity of said political Charter; to achieve this, historical-legal and socio-legal research were combined, under a mixed (theoretical-empirical) quantitative and hermeneutical approach, that allowed concluding the existence of an authoritarian substratum in the judicial government under the regenerationist constitution, which imposed a harmful administrative and guardianship control of the executive in judicial affairs, on which the resistance of the legal structure to hosting transit would be built, towards the judicial autarchy that was proposed as a solution to the problems that affected the administration of justice.
\end{abstract}

Keywords: judicial branch; Judicial Revolving Fund; Ministry of Justice; judicial administration; judicial self-government; administrative and guardianship control; Constitution of 1886. 


\section{INTRODUCCIÓN}

Este artículo se presenta como avance de un proyecto de investigación denominado Autarquía judicial en Latinoamérica: antecedentes, alcances, logros y retos, desarrollado con recursos propios y en mi calidad de miembro del Grupo de Investigación Frater Juris avalado por la Universidad Popular del Cesar. En este proyecto, participo como único investigador.

En la Constitución colombiana de 1991 se efectuaron transformaciones al Estado existente. Se trató de una adaptación de este a nuevas exigencias políticas, económicas y sociales que se hacían necesarias para la modernización del Estado, la trasparencia y democratización de la gestión pública, el impulso industrial y económico, la reconstrucción del tejido social y de la confianza en las instituciones estatales.

La rama judicial no fue ajena a estos cambios, pues se encontraba afectada por diversos factores, como la baja capacidad para enfrentar las presiones de los actores violentos de la época (narcotraficantes, guerrillas y paramilitares) o su incapacidad para responder a las demandas sociales de justicia que se hacían evidentes en su morosidad. A mediados de los ochenta había aproximadamente dos millones de expedientes en lo civil, por lo que los jueces debían resolver cerca de cincuenta procesos por millón de habitantes. En lo penal, el 20 \% de los delitos cometidos eran de conocimiento de las autoridades, y de ese 20 \% solo un 4 \% llegaban a sentencia, sin que eso significara una sanción efectiva a los responsables (Uprimny, 1997).

La confianza ciudadana en la justicia era baja, y para lograrla se debía romper con las condiciones que la generaban. La rama judicial, así como todo el Estado, debía evolucionar. Para ello, era indispensable profundizar en su independencia sustantiva y estructural, entendidas como la autonomía del juez para emitir sus decisiones al margen del Ejecutivo y el Legislativo y, por otro lado, la organización institucional que permita la independencia sustantiva de la rama (Salzberger, 1993, citado en Franco, 1997).

La Constituyente de 1991 pretendió, entonces, agudizar la independencia de la rama judicial. Por ello, no solo entregó la facultad de administrar justicia, sino la posibilidad de que esta pudiera ejecutar las actividades necesarias para su operatividad administrativa y la obtención de los bienes y servicios requeridos para su funcionamiento, es decir, la dotó inequívocamente de función administrativa.

El artículo 116 de la Constitución política nacional, que definió los órganos que administran justicia, determinó el nacimiento del Consejo Superior de la Judicatura, y el artículo 256 constitucional transfirió a dicho tribunal las competencias de administrar la carrera judicial y de elaborar el proyecto de presupuesto de la rama judicial (Constitución Política de Colombia, 1991). Además, definió su ejecución, lo que traduce nuestra honorable Corte Constitucional como el principio de autogobierno judicial (Sentencia C-285/16, 2016). Este tuvo que ser recientemente defendido por el Tribunal Constitucional 
respecto de las pretensiones de un nuevo modelo de gobierno y administración de la rama judicial que había sido plasmado en el Acto Legislativo 02 (2015).

Este principio de autogobierno, del que versa la Sentencia C-285/16 (2016) proferida por la Corte Constitucional, insertado en nuestra carta fundamental debido a la potestad interpretativa de este alto tribunal, se constituye hoy en un principio cardenal de nuestra rama judicial. Este es importante ya que en el pasado era inexistente, por lo que "el Poder Judicial" otrora gozaba de independencia respecto de su función principal —administrar justicia—, pero no tenía autonomía administrativa.

Recordemos que la Constitución de 1886 se cimentó en el ideario liberal clásico, el cual usó un criterio eminentemente orgánico en la distribución de poderes, lo que implicaba que la administración incrementaba sus atribuciones en detrimento de la jurisdicción (Olarieta, 2011).

Esta es la razón por la cual, bajo la concepción clásica de división del poder, la rama judicial no tenía posibilidades de autogobernarse, pues debía circunscribirse a la administración de justicia y no gozaba de función administrativa. En el informe de la sesión de la comisión tercera de la Asamblea Nacional Constituyente de Colombia, realizada el 15 de mayo de 1991, se advierte que los constituyentes lucharon contra esta separación estricta de las ramas del poder:

Hoy es claro que ya no existe esa separación estricta en compartimientos... entre los órganos o las ramas del poder que concebía Montesquieu y que concebía la doctrina clásica tradicional del Estado y que los órganos, o las ramas, o los poderes, o como queramos llamarlos, ejercen funciones específicas pero pueden ejercer otras funciones que son propias o características de otras ramas. (Presidencia de la Republica, 1991, p. 27)

Visto lo anterior, surge la inevitable pregunta: ¿El principio de autogobierno judicial es propio de la Constitución de 1991, por lo que antes de esta primaba la separación orgánica y estricta de división del poder? ¿Cómo se ejercía el gobierno de la rama judicial colombiana durante la vigencia de la Constitución de 1886?

Para responder este interrogante se abordó una investigación tanto históricojurídica como sociojurídica. De esta manera, se pudo estudiar y delimitar al gobierno judicial en el pasado, ubicar el sustrato sociopolítico de su implementación jurídica y la interrelación entre las normas que regulaban este fenómeno con la coyuntura político-social de ese entonces. Lo anterior implicó un análisis documental, tanto de normas jurídicas como de doctrina, bajo un enfoque mixto (teórico-empírico) cuantitativo y hermenéutico.

\section{GOBIERNO JUDICIAL BAJO LA CONSTITUCIÓN DE 1886, DURANTE EL SIGLO XIX}

La Constitución de la República de Colombia de 1886, promulgada un 5 de agosto de esa anualidad, es uno de nuestros hitos jurídicos más importantes junto con la actual 
Carta Magna, pues nos rigió durante casi ciento cinco años, exactamente hasta el 4 de julio de 1991, es decir, más de un siglo de nuestra historia y vida republicana fue configurada bajo su mandato, lo que dejó en nosotros profundas huella políticas, sociales y económicas.

La Constitución del 86 se enmarcó en el ideario clásico liberal —no el liberalismo colombiano- de separación del poder, tergiversado por los momentos históricos de la época, pues impuso un Estado autoritario, como sostuvo Rafael Núñez (1885) en el Consejo Nacional Delegatario que se reunió en noviembre de 1885: "Las repúblicas deben ser autoritarias, so pena de incidir en permanente desorden" (p. 7).

Ese autoritarismo de que trató Núñez se vio reflejado en la acentuación del presidencialismo en Colombia. Así, amplió los poderes y facultades del Ejecutivo al introducir artículos que le permitían cierta capacidad de supeditar a los demás poderes públicos (Melo, 1989) en lo que parece hacer cierta la tesis de Hauriou (2019) de que no hay más poder que el ejecutivo.

En efecto, a pesar de que la teoría e incluso la constituciones demoliberales proclamaban la separación de los poderes y, por ende, la independencia judicial, en la práctica sucedió la dependencia de lo judicial al ejecutivo a través de un poder de tutela que le permitía una amplia intromisión en los asuntos judiciales (Estaran, 2007). En este sentido, Pérez (2018) manifiesta que la realidad cotidiana de la independencia judicial en el siglo XIX es:

un spoil system puro y duro; en la continua injerencia, incluso en etapas de gobiernos progresistas, del gobierno en la judicatura, que se hacía directamente a través no sólo de los nombramientos, sino de los traslados y ceses, en la inmensa mayoría de los casos por motivos estrictamente políticos. (p. 63)

Esta injerencia se materializó en la Constitución de 1886, con el artículo 119, que facultó al presidente de la República para nombrar a los magistrados de la Corte Suprema y a los magistrados de los tribunales superiores, de ternas que presentaba la Corte Suprema, lo que implicaba una dependencia burocrática de los magistrados al Poder Ejecutivo.

A través de la Ley 7 (1886) se crean los ministerios que hacen parte del despacho administrativo del Gobierno. De esta manera, se determina el nacimiento del Ministerio de Gobierno, el primero en precedencia, y al cual se le encarga, entre muchas atribuciones, de la Corte Suprema, tribunales y juzgados (Ministerio del Interior, s.f.). El antecedente remoto de este ministerio se encuentra en la Secretaria de Gracia y Justicia que hacía parte del Consejo Ejecutivo de la Junta Revolucionaria de Santafé de Bogotá y que atendía las cuestiones administrativas de lo judicial (Barrera, 1998).

Tan solo tres meses después de la creación del Ministerio de Gobierno, se crea la Ley 61 (1886) que, siendo coherente con la Constitución, determina el control 
del Ejecutivo sobre las vacantes de magistrados de la Corte Suprema y tribunales superiores. Sin embargo, permite que sean estos últimos quienes nombren a los jueces superiores de distrito y a los jueces de circuito mediante la aprobación de la Corte Suprema de Justicia, pero con la intervención del respectivo fiscal del tribunal, el cual era agente directo del presidente de la Republica. En lo que respecta a los jueces municipales, la Ley 61 (1886) atribuye la competencia de su nombramiento a los concejos municipales, con la aprobación del juez $1^{\circ}$ de lo civil del circuito.

Ahora bien, en lo correspondiente a los bienes y servicios necesarios para que los despachos judiciales operaran, el artículo 143 de la Ley 61 (1886) dispuso que las asambleas departamentales, por medio de sus ordenanzas, debían proveer a los tribunales superiores y juzgados los locales, muebles, útiles y todo elemento necesario para el cumplimiento de su función de modo decente y cómodo.

Como puede verse, el Poder Ejecutivo estableció sobre el Poder Judicial un control o injerencia de tipo administrativa que, en el fondo, solo puede entenderse como una medida de carácter político que permitía controlar a los jueces y encausarlos por las vías de la regeneración de Rafael Núñez.

Al año siguiente, con la Ley 153 (1887), se ampliaron las competencias injerencistas del Ejecutivo, quien a través del Ministerio de Gobierno, así como a través de las secretarías departamentales generales o de Gobierno, inspeccionaría cada mes a la Corte Suprema y a los tribunales. Así, se verificaría el estado de los procesos y la moratoria judicial, con lo que se consolida un control de tutela y administrativo que radica el gobierno judicial en el Poder Ejecutivo.

En 1890, se crea el Ministerio de Justicia a través de la Ley 13 (1890) para la vigilancia y auxilio del Poder Judicial. Se toman las competencias que tenía el Ministerio de Gobierno en la inspección y dirección administrativa del Poder Judicial, con lo que se lograba una desconcentración que permitiría mayor atención del Gobierno nacional a los asuntos de gobierno judicial y las disposiciones de la Ley 61 (1886) siguieron vigentes.

El Ministerio de Justicia inicial fue de corta duración, pues mediante la Ley 11 (1894) fue suprimido presuntamente por adelantar una investigación sobre la ejecución contractual en el marco de la construcción de los ferrocarriles de Antioquia y de Santander (Ministerio de Justicia, s.f.). Por ello, sus funciones fueron regresadas al Ministerio de Gobierno mediante el Decreto 1238 (1894). Así las cosas, el gobierno judicial se mantuvo en el Poder Ejecutivo a través del Ministerio de Gobierno, las asambleas departamentales y los consejos municipales. 


\section{GOBIERNO JUDICIAL BAJO LA CONSTITUCIÓN DE 1886 DURANTE EL SIGLO XX}

El régimen regeneracionista, que había dado nacimiento a la Constitución de 1886 , de la mano de Rafael Núñez y Miguel Antonio Caro en los inicios del siglo XX, se sentía fallido. La "paz científica" de Núñez no se logró y, en cambio, la constitución fue un catalizador de guerras civiles que costaron sangre de miles de colombianos y la separación de Panamá. Esto llevó en 1909 al entonces presidente Ramón González a convocar una Asamblea Nacional Constituyente para regenerar a la regeneración.

El proceso constituyente finalizó con la promulgación del Acto Legislativo 3 (1910), Reformatorio de la Constitución nacional, que buscó atenuar un poco el poder presidencial. Así, en lo concerniente al Poder Judicial trasfirió al Congreso nacional la competencia para elegir a los magistrados de la Corte Suprema de Justicia y sus suplentes a partir de ternas que presentaba el presidente de la República. A su vez, los magistrados de los tribunales superiores y sus suplentes serían nombrados por la Corte Suprema de las ternas presentadas por las asambleas departamentales; y los consejos municipales nombrarían a los jueces.

Mediante la Ley 88 (1910), el auxilio administrativo a tribunales y juzgados, que hasta entonces se radicaba en las asambleas departamentales, pasa a ser responsabilidad de los gobernadores; mientras que el de la Corte Suprema lo conserva el Ministerio de Gobierno a través de una oficina denominada Dirección de Justicia.

Con la Ley 68 (1945) se recrea el Ministerio de Justicia, entidad que tendría a su cargo la organización, protección y vigilancia de la rama judicial, lo cual no hace sino centralizar en el Gobierno nacional todo lo relativo al funcionamiento administrativo de la rama. En este sentido, se arrogó la competencia que hasta esos momentos le correspondía a los gobernadores, asambleas departamentales y consejos municipales, respecto de tribunales superiores y juzgados.

Por medio del Decreto 105 (1947) se organiza el Ministerio de Justicia y se crea al Departamento de Vigilancia de la Rama Jurisdiccional y del Ministerio Público con la potestad para llevar el registro de los funcionarios de la rama, formular quejas disciplinarias de los mismos ante el ministro, examinar y resolver todo lo relacionado con el movimiento de fondos, valores y demás efectos de los tribunales y juzgados. Además, dispone la existencia de un departamento jurídico, del cual dependería todo el personal de jueces y empleados que integran el Cuerpo Auxiliar de la Rama Jurisdiccional, incluyendo los del servicio de aseo y conserjería.

En el año de 1954 se crea el Fondo Rotatorio Judicial mediante el Decreto 1709 (1954), una entidad administrativamente autónoma con personería jurídica independiente y patrimonio propio, vinculada al Ministerio de Justicia, cuya función sería la de mejorar la dotación y funcionamiento material de las oficinas de la rama jurisdiccional del poder público. A través del Decreto 2404 (1955) se reglamenta dicho fondo y se 
dispone que este será administrado por una junta directiva y un gerente que será su representante legal.

El artículo séptimo del Decreto 2404 (1955) planteó la siguiente conformación de la Junta Directiva del Fondo Rotatorio Judicial:

- El ministro de justicia, o el funcionario que él designe, quien la presidirá;

- Un representante de los magistrados y jueces de la rama jurisdiccional;

- Un representante de los funcionarios del Ministerio Público;

- Un representante de los empleados subalternos de la rama jurisdiccional y del Ministerio Público;

- Un representante de los empleados del Ministerio de Justicia y del Cuerpo Auxiliar de la Rama Jurisdiccional.

Por otra parte, el Decreto 2404 (1955), en las prescripciones sobre la escogencia de los miembros de la Junta, le da una amplia participación al presidente de la República, como podemos ver a continuación:

El representante de los magistrados y jueces será escogido por el presidente de la República, de terna que envíe la Corte Suprema de Justicia, por conducto del Ministerio;

El representante de los funcionarios del Ministerio Público será escogido por el presidente de la República, de terna que le envíe el procurador general de la nación, por conducto del Ministerio;

El representante de los empleados subalternos será escogido por el Ministro de Justicia;

El representante de los empleados del Ministerio de Justicia v del Cuerpo Auxiliar de la Rama Jurisdiccional, será el secretario general del Ministerio. (Decreto 2404, 1955, art. 8)

La escogencia de los miembros de la Junta Directiva coartó toda posibilidad de autonomía del Fondo, el cual estaba absolutamente dominado por el Ejecutivo, que para ese entonces estaba en manos del General Rojas Pinilla.

El establecimiento del Fondo Rotatorio de la rama Judicial fue un intento para modernizar la justicia en Colombia. Pero, como expresa Barrera (1998), todo desemboca en inconformidades por fallas en el servicio de justicia, la impunidad, la alta politización de los jueces y las bajas calidades de los abogados. Todo esto se pretendió conjurar con el Decreto 251 (1957), por el cual la Junta Militar del Gobierno implantó la cooptación, la inamovilidad de los magistrados y el sistema paritario tanto en la Corte Suprema de Justicia, como en el Consejo de Estado. 
La Junta Militar llegó a su fin el 7 de agosto de 1958, con lo cual soplaron aires de renovación democrática en Colombia, y la relativa calma del Frente Nacional permitió abordar con mayor tranquilidad los problemas de la rama judicial. Por otro lado, el Decreto 1716 (1960) reorganizó al Ministerio de Justicia y confirmó su función de administración, vigilancia y control sobre la justicia, pero realizó una profunda desconcentración administrativa.

Con el Decreto 1716 (1960) surge la división de vigilancia judicial en el Ministerio de Justicia, encargada de dirigir y coordinar los trabajos relacionados con la asistencia administrativa a la rama jurisdiccional y con el registro de personal de esta rama. Así, el Fondo Rotatorio Judicial se encargó de la protección social de los funcionarios.

El presidente Carlos Lleras Restrepo emitió noventa decretos en 1969 por atribuciones conferidas mediante la Ley 16 (1968), la cual usó para establecer nuevas divisiones jurisdiccionales, emitir códigos y hasta para establecer la carrera judicial o el estatuto de la abogacía (Barrera, 1998). Y Misael Pastrana Borrero, con el Decreto 1208 (1973), reorganizó el Fondo Rotatorio del Ministerio de Justicia; le sumó a su funciones ya existentes planificar y ejecutar obras de construcción de manera coordinada con el Ministerio de Obras Públicas, así como todo lo correspondiente al arrendamiento de locaciones: suministro de equipos, útiles y enseres, dotación de servicios públicos domiciliarios, entre otros.

Lo anterior se planteó con el firme propósito de brindarle a la república un sistema judicial moderno y competente, pero Colombia se vería abocada a afrontar nuevas épocas de crisis. Las Fuerzas Armadas Revolucionarias de Colombia [FARC] aparecieron en 1964, el Ejército de Liberación Nacional [ELN] lo hizo al año siguiente (1965) y el Ejército Popular de Liberación [EPL] apareció en 1967. Por otra parte, el narcotráfico venía incubándose en el territorio nacional desde principios de siglo, y tras la Segunda Guerra Mundial se perfilaba como un negocio lucrativo (Sáenz, 1996).

Finalizado el Frente Nacional en 1974, las instituciones del gobierno judicial no habían variado en esencia. El control del Ejecutivo frente a los asuntos administrativos de la rama seguían incólumes y se ejercían a través del Ministerio de Justicia y del Fondo Rotatorio Judicial, en el marco de una situación de miseria presupuestal y de recursos (Arrubla, 2013) que perjudicó la imagen institucional de la rama, pues los juzgados son insuficientes e ineficientes (Barrera, 1998).

En 1977, Alfonso López Michelsen, a través del Acto Legislativo 2 (1977), convocó a la denominada "pequeña constituyente" que se derivaba del Congreso y que tuvo como uno de sus ejes principales la reforma de la administración de la justicia. Pero esta no prosperó porque la Corte Suprema de Justicia, a través del Acta 17 (1978), lo declaró inexequible al considerar que el Congreso no puede subdelegar el poder de reforma de la carta política. 
Un segundo momento de reforma a la justicia en la década de los setenta del siglo XX, se presentó con el Acto Legislativo 1 (1979) que formuló los primeros pasos del autogobierno judicial en Colombia. Este incorporó medidas como la cooptación, la carrera judicial, la permanencia larga pero temporal de los magistrados en sus cargos (ocho años) y sin reelección. Además, incluyó un sistema paritario y, lo más importante, en su artículo 44 creó un Consejo Superior de la Judicatura.

A ese Consejo Superior de la Judicatura, el Acto Legislativo 1 (1979) le atribuyó administrar la carrera judicial, participar en la elaboración de lista de elegibles para magistrados de las altas cortes, tribunales y jueces, el control disciplinario de funcionarios y empleados de la rama jurisdiccional, entre otras que cimientan hoy el gobierno de la rama judicial.

El Gobierno de Turbay Ayala, mediante Decreto 3266 (1979), reglamentó el Consejo Superior de la Judicatura y lo dividió en dos secciones: la sección de carrera judicial y sección disciplinaria. La primera quedó la primera con las siguientes funciones:

La sección de la carrera judicial tendrá las siguientes funciones:

$1^{a}$.- Estudiar, analizar y concordar la legislación sobre carrera judicial;

$2^{\mathrm{a}}$ - Tramitar y sustanciar lo concerniente a la administración de la carrera judicial;

$3^{a}$.- Diligenciar los asuntos relacionados con la expedición del estatuto de carrera judicial, a fin de proveer lo necesario para su organización y funcionamiento y adelantar los estudios técnicos tendientes a dichas finalidades;

$4^{\text {a }}$ - Llevar el registro de los funcionarios y empleados de la Rama Jurisdiccional, con sus hojas de vida y el registro de las novedades;

5ª - Las demás que le señale la ley o los reglamentos. (Decreto 3266, 1979, art. 9)

Así las cosas, quedó en manos del Consejo Superior de la Judicatura lo concerniente a la administración de la carrera judicial y bajo la acción del Ministerio de Justicia, a través del Fondo Rotatorio Judicial, los aspectos relativos a la protección social de los funcionarios judiciales, la contratación de obras de infraestructura y mantenimientos, así como la adquisición de bienes y servicios.

Mediante el Decreto 3266 (1979) y el Decreto 1064 (1980), el Gobierno nacional dispuso todo lo pertinente para el cabal funcionamiento institucional del Consejo Superior de la Judicatura. Pero a pesar de los significativos avances para la independencia de la rama judicial, la Corte Suprema de Justicia declaró en la Sentencia 786 (1981) que, por vicios en su conformación, el Acto Legislativo 1 (1979) era inexequible en su totalidad, con lo que finalizó así este periodo del Consejo Superior de la Judicatura. 
Llegada la década de los años ochenta, el Estado hace esfuerzos ingentes para mejorar el funcionamiento de los despachos judiciales. Tal vez el más significativo de estos esfuerzos fue la ley de emergencia judicial (Ley 22, 1980). Pero los grupos delincuenciales y los actores del conflicto armado se emplearon a fondo para socavar la independencia judicial, de tal forma que los pocos avances se verían ensombrecidos por los acontecimientos de la época.

Los años ochenta del siglo pasado fueron una época aciaga para la justicia en Colombia. A los grupos guerrilleros y carteles de narcotráfico, se sumaba el incipiente paramilitarismo, por lo que las amenazas a jueces y magistrados se volvieron rutinarias: se atentaba contra su vida, su integridad personal, sus bienes y familia, y se les amedrentaba de diferentes formas para incidir en su función constitucional. El caso más tenebroso fue la toma y la retoma del Palacio de Justicia en 1985, en donde fueron inmolados once magistrados, con un saldo total de noventa y ocho personas fallecidas.

El Ministerio de Justicia también es víctima del terror. Los casos más destacados son el homicidio del ministro Rodrigo Lara Bonilla, asesinado por sicarios de Pablo escobar en 1984; el atentado de 1987 contra el exministro de justicia Enrique Parejo González, realizado en Budapest (Hungría) también por órdenes de Escobar; y el asesinato del exministro Enrique Low Murtra en 1991 a la salida de la Universidad de La Salle (Bogotá) presuntamente por mandato de Los Extraditables.

De conformidad con Zubiría (2012), antes del establecimiento de la Constitución de 1991 se intentó una última reforma a la justicia. Durante la Administración de Virgilio Barco, este presentó en 1988 un proyecto aprobado en primera vuelta en el legislativo, que no llegó a concretarse, donde se planteaba la creación de un consejo superior de administración judicial.

Entrada Colombia en los años noventa del siglo XX, la rama judicial se encontraba supeditada a lo administrativo por el Ejecutivo, quien a través del Ministerio de Justicia y su Fondo Rotatorio Judicial disponían lo concerniente al gobierno de esa rama, lo que iba desde la adquisición de una hoja de papel hasta la construcción o mantenimiento de la infraestructura física necesaria.

Al ser la rama judicial un subordinado del Ministerio de Justicia y del poder presidencial, sus acciones eran limitadas para obtener los recursos suficientes que le permitieran operar, lo que hacía de los juzgados instituciones lentas y hasta odiosas para los administrados. Todos estos aspectos causaron la crisis de la justicia, como bien lo señaló la delegataria de la Asamblea Nacional Constituyente, María Teresa Garcés Lloreda (Zubiría, 2012). Según ella, la crisis judicial se debió a la falta de autonomía administrativa y financiera; la insuficiencia de jueces y magistrados; la carencia de recursos económicos y elementos de trabajo; la falta de generalización de una carrera judicial; y unos procedimientos judiciales largos y complicados, llenos de formalismos. 
La crisis de la justicia se adjudicaba en buena medida a la interferencia del Ejecutivo, por lo que la Asamblea Nacional Constituyente determinó dotarla de total independencia de las otras ramas del poder público. Así, incorporó en la rama judicial un órgano que, de manera autárquica, le permitiera gestionar sus asuntos administrativos, lo que incluiría lo referente al control disciplinario de sus funcionarios y dirigir la carrera judicial: renace el Consejo Superior de la Judicatura.

\section{FINALIZACIÓN DEL GOBIERNO JUDICIAL POR PARTE DEL EJECUTIVO}

El artículo 116 constitucional incorpora al Consejo Superior de la judicatura en la rama judicial, mientras que los artículos 256 y 257 le confieren sus atribuciones como gobierno de la rama:

- Administrar la carrera judicial.

- Examinar la conducta y sancionar las faltas de los funcionarios de la rama judicial, así como las de los abogados en el ejercicio de su profesión, en la instancia que señale la ley.

- Llevar el control de rendimiento de las corporaciones y despachos judiciales.

- Elaborar el proyecto de presupuesto de la rama judicial que deberá ser remitido al Gobierno, y ejecutarlo de conformidad con la aprobación que haga el Congreso.

- Fijar la división del territorio para efectos judiciales y ubicar y redistribuir los despachos judiciales.

- Crear, suprimir, fusionar y trasladar cargos en la administración de justicia. En ejercicio de esta atribución, el Consejo Superior de la Judicatura no podrá establecer a cargo del Tesoro obligaciones que excedan el monto global fijado para el respectivo servicio en la ley de apropiaciones iniciales.

- Dictar los reglamentos necesarios para el eficaz funcionamiento de la administración de justicia, los relacionados con la organización y funciones internas asignadas a los distintos cargos y la regulación de los trámites judiciales y administrativos que se adelanten en los despachos judiciales, en los aspectos no previstos por el legislador.

- Proponer proyectos de ley relativos a la administración de justicia y a los códigos sustantivos y procedimentales. (Constitución Política de Colombia, 1991)

Posteriormente, se expide el Decreto 2652 (1991) por el cual el Fondo Rotatorio Judicial pierde total competencia en relación con la rama judicial y debe hacer entrega al Consejo Superior de la Judicatura de los bienes que haya adquirido para la justicia. 
Finalmente, el Fondo desaparece cuando se fusiona con la Dirección General de Prisiones del Ministerio de Justicia (Decreto 2160, 1992) dando nacimiento al Instituto Nacional Penitenciario y Carcelario (Inpec).

En la Constitución de 1991, de conformidad con la Sentencia C-285 (2016) de nuestra honorable Corte Constitucional, el constituyente incorporó el principio de autogobierno judicial. En este sentido, rompió con siglos de tradición injerencista del Ejecutivo en los asuntos judiciales a través de un poder de tutela y administración que impedía una total independencia entre esas expresiones del poder público, lo cual creó así desconfianza en la justicia.

Para enfatizar la idea anterior, me permito finalizar citando a Valdés (2004):

En un panorama de incertidumbre causado por la polarización de las fuerzas políticas, lo mismo que en un ambiente de relaciones políticas en equilibrio, los órganos de impartición de justicia juegan un papel medular: Se mantienen como un referente que ofrece una garantía de imparcialidad a los agentes políticos y a la sociedad. Por eso en los procesos de transición democrática es prioritario fortalecer la Judicatura en todos los sentidos: profesional, técnico y autárquico. (p. 135)

\section{CONCLUSIONES}

En la Constitución de 1886, el poder judicial —hoy rama judicial—, respondiendo a las premisas autoritarias y centralistas de la regeneración de Rafael Núñez y Miguel Antonio Caro, quedó supeditado en lo administrativo al poder ejecutivo. La regeneración, como sustrato sociopolítico, logró consolidar un sistema jurídico a su antojo en el cual las acciones que permitían a la judicatura proveerse de los bienes y servicios necesarios para su operación institucional estaban bajo su control jurídico.

El fundamento teórico que sustentó la capacidad de ejercer el gobierno judicial por el ejecutivo fue la separación orgánica de las funciones del Estado que justificaba la abierta intención política regeneracionista de sepultar el "laissez faire, laissez passer" e implantar un autoritarismo que permitiera consolidar su anhelada hegemonía conservadora. De esta manera, evitó los obstáculos que pudiera representar un poder judicial realmente autónomo e independiente.

La regeneración, al poder interferir en la designación de los magistrados y jueces, lograba ubicar a sus acólitos en los altos cargos del poder judicial. Con ello, el Ejecutivo colocaba a la burocracia judicial al servicio de un ideario político para garantizar la plena capacidad para poder redirigir toda expresión socioeconómica según su agenda de hegemonía cultural.

El sometimiento de la administración de lo judicial al Ejecutivo trajo consigo graves perjuicios a la función eminentemente judicial, que se evidenciaron en diferentes aspectos: 
- Esfuerzos normativos para frenar la moratoria judicial.

- Incapacidad institucional de la Presidencia para ejercer con eficiencia y transparencia el gobierno de la administración de justicia.

- Constante implementación y abandono de transformaciones jurídicas en lo funcional e institucional para el gobierno de lo judicial.

Transcurrió más de medio siglo para que se creara una figura más o menos óptima que, desde la rama ejecutiva, pudiera atender la complejidad de la administración de la justicia: el Fondo Rotatorio Judicial. Entre sus más importantes características, estaba contar con autonomía administrativa, personería jurídica propia y patrimonio independiente. Esto quiere decir que se empezó a reconocer que, para lograr un gobierno judicial eficaz, se hacía necesario que se gestionara con autonomía e independencia.

Pero, a pesar de lo anterior, la realidad política colombiana superó la realidad jurídica, lo que hizo del Fondo Rotatorio una rueda más del engranaje político del Gobierno nacional. En este sentido, la institución no operó con independencia, pues inmediatamente surgieron normas jurídicas que obstaculizaron tal característica:

- El Decreto 2404 (1955) en lo relacionado con la conformación de la Junta Directiva del Fondo Rotatorio Judicial.

- El Decreto 1716 (1960) que regresó al Ministerio de Justicia, a través de la División de vigilancia judicial, a la asistencia administrativa de la rama, con lo que el Fondo Rotatorio quedó con la gestión de la protección social de los funcionarios.

El socavamiento de la autonomía de la rama judicial por parte del Ejecutivo dio al traste con toda intención de modernizar al sector de la justicia, a pesar de que se adoptaron medidas como la inamovilidad de los magistrados, el sistema paritario, nuevas divisiones jurisdiccionales, el establecimiento de la carrera judicial o el estatuto de la abogacía.

A finales del siglo XX, la política de sometimiento y tutela del Ejecutivo en cuanto al gobierno de la rama judicial había demostrado ser inconveniente, por lo que empezó a aumentar la voluntad política de ahondar en una descentralización que le permitiera a la rama gobernarse por sí misma. Por esta razón, realizar una reforma a la justicia se convirtió en un apremio fundamental que se intentó materializar a través del Acto Legislativo 2 (1977) y el Acto Legislativo 1 (1979), ambos declarados inexequibles por la Corte Suprema de Justicia.

De las anteriores reformas a la justicia, se destaca la que se estableció mediante el Acto Legislativo 1 (1979), pues incorporó por primera vez en Colombia un sistema de autogobierno de la rama judicial: 
- Elección de magistrados por cooptación.

- Carrera judicial.

- Permanencia larga y temporal de magistrados en sus cargos (ocho años) sin posibilidad de reelección.

- Sistema paritario.

- Consejo Superior de la Judicatura como órgano de gobierno judicial: administración de la carrera judicial; control disciplinario de los funcionarios judiciales; participación en elección de magistrados y jueces.

En 1979 y 1980, con la voluntad política del Gobierno nacional, se hicieron grandes avances en materia de autogobierno judicial. Pero el 3 de noviembre de 1981, la Corte Suprema de Justicia declaró la inexequibilidad del Acto Legislativo 1 (1979). Con ello, dio un golpe definitivo a las intenciones independentistas de la justicia frente a la rama ejecutiva, del cual no volvería a recuperarse hasta la implantación de la Constitución de 1991. Esta volvió a quedar, entonces, en manos del Ministerio de Justicia y del Fondo Rotatorio Judicial.

Tras la declaración de inexequibilidad del Acto Legislativo No.1 (1979), las inconformidades del sistema de justicia - tanto internas por la precariedad de recursos como externas por las deficiencias en la prestación del servicio-, se mantienen. Con ellas, también se mantiene el deseo de lograr una transformación que permita a la justicia lograr su modernización y eficiencia, lo cual se traducía en un gobierno autárquico del sistema, que solo se logró hasta la implementación de la Constitución de 1991.

La resistencia de la estructura jurídica de la Constitución de 1886 para acoger los cambios de autarquía que requería la administración de lo judicial, en consonancia con los ingentes esfuerzos infructíferos por conseguirla, demuestra en la importancia del autogobierno judicial para muchos actores políticos y jurídicos de la época que vislumbraban una independencia sustantiva de la rama para romper los escollos que significaban para el cabal cumplimiento de los fines de la administración de justicia, el control administrativo y de tutela que ejercía el Gobierno.

\section{REFERENCIAS}

Asamblea Nacional Constituyente (1991, 20 de julio). Constitución Política de Colombia de 1991. Gaceta Constitucional n. ${ }^{\circ}$ 116. https://www.funcionpublica.gov.co/eva/gestornormativo/norma.php?i=4125

Arrubla, J. (2013). Las relaciones entre los poderes públicos, la función de los jueces y la independencia judicial: análisis para una propuesta de reforma a la justicia. En D. Remolina Botía (ed.), Aproximación a la historia de una década de transformaciones en la justicia colombiana (pp. 153-181). Corporación Excelencia en la Justicia; Legis. 
Barrera, E. (1998). Reformas para la modernización y efectividad de la justicia en Colombia. En O. Guerrero (comp.), El papel de los ministerios de justicia en la reforma del Estado (pp. 55 - 136). Instituto de Investigaciones Jurídicas de la UNAM. https://biblio.juridicas.unam.mx/bjv/id/124

Congreso de Colombia (1890, 13 de octubre). Ley 13 de 1890. Por la cual se crea el Ministerio de Justicia y se derogan los artículos 10 y 20 de la Ley 28 de 1888. Diario Oficial n. ${ }^{\circ} 8210$. https://n9.cl/qcivc

Congreso de Colombia (1894, 25 de septiembre). Ley 11 de 1894. Sobre el número, nomenclatura y precedencia de los Ministerios del Despacho Ejecutivo. Diario Oficial n. ${ }^{\circ}$ 9596. https://n9.cl/kvh5

Congreso de Colombia (1945, 21 de diciembre). Ley 68 de 1945. Por la cual se crea el Ministerio de Justicia y se confirman unas autorizaciones. Diario Oficial n. ${ }^{\circ}$ 26019. https://n9.cl/0v2c3

Congreso de Colombia (1968, 28 de marzo). Ley 16 de 1968. Por la cual se restablecen los juzgados de Circuito, se dictan normas sobre competencia en materia penal, civil y laboral, se dan unas autorizaciones y se dictan otras disposiciones. Diario Oficial n. ${ }^{\circ}$ 32467. https://n9.cl/yemt

Congreso de Colombia (1977, 19 de diciembre). Acto Legislativo 2 de 1977. Por el cual se reforma la Constitución Nacional. Diario Oficial n. ${ }^{\circ}$ 34935. https://n9.cl/alzm

Congreso de Colombia (1979, 4 de diciembre). Acto Legislativo 1 de 1979. Por el cual se reforma la Constitución Nacional. Diario Oficial n. ${ }^{\circ}$ 35416. https://n9.cl/cxm48

Congreso de Colombia (1984, 17 de septiembre). Ley 22 de 1984. Por la cual se reconoce la Biología como una profesión, se reglamenta su ejercicio en el país y se dictan otras disposiciones. Diario Oficial n. 36768. https://n9.cl/vd6b

Congreso de Colombia (2015, 1 de julio). Acto Legislativo 2 de 2015. Por medio del cual se adopta una reforma de equilibrio de poderes y reajuste institucional y se dictan otras disposiciones. Diario Oficial n. ${ }^{\circ} 49560$. https://n9.cl/g3yph

Consejo Nacional Legislativo (1886, 25 de agosto). Ley 7 de 1886. Sobre el número, nomenclatura y precedencia de los Ministerio del Despacho Ejecutivo. Diario Oficial n. ${ }^{\circ}$ 6785. https://n9.cl/o7 lfe

Corte Constitucional (2016, 1 de junio). Sentencia C-285/16. (Luis Guillermo Guerrero, M. P.). http:// www.corteconstitucional.gov.co/RELATORIA/2015/C-285-15.htm

Corte Suprema de Justicia (1978, 5 de mayo). Sentencia aprobada en acta 17 (José María Guerrero, M. P.). https://n9.cl/bfqwk

Corte Suprema de Justicia (1981, 3 de noviembre). Sentencia en expediente número 786 (Fernando Uribe Restrepo, M. P.). https://n9.cl/qt5ps

Consejo Nacional Constituyente (1886, 4 de agosto). Constitución política de la República de Colombia de 1886. https://n9.cl/s4ig7

Consejo Nacional Legislativo (1886, 25 de noviembre). Ley 61 de 1886. Provisional sobre organización y atribuciones del Poder Judicial y el Ministerio Público y algunos procedimientos especiales. Diario Oficial n. ${ }^{\circ}$ 6.881-6.882. https://bibliotecadigital.ccb.org.co/handle/1 1520/13854

Estaran, J. M. (2007) La justicia a finales del siglo XIX. Un caso concreto: la audiencia de lo criminal de Manresa (1882-1892) [tesis de doctorado, Universitat Rovira i Virgili]. Repositorio Institucional URV. http:// repositori.urv.cat/estatic/TDX0011/es_TDX545.html

Franco, A. (1997, 17 de abril). Independencia Judicial y Política en Colombia [ponencia]. Latin American Studies Association, Guadalajara, México. http://lasa.international.pitt.edu/LASA97/franco.pdf 
Gobierno Ejecutivo (1887, 15 de Agosto). Ley 153 de 1887. Por la cual se adiciona y reforma los códigos nacionales, la ley 61 de 1886 y la 57 de 1887. Diario Oficial n. ${ }^{\circ}$ 7.151-7.152. https://n9.cl/50tas

Hauriou, M. (2019). Principios de Derecho público y constitucional. Olejnik. (Original publicado en 1927)

Junta Militar de Gobierno de la República de Colombia (1957, 9 de octubre). Decreto 251 de 1957. Por el cual se sustituye el artículo 12 del texto indivisible sobre reforma a la Constitución Nacional, sometido a plebiscito mediante el Decreto legislativo número 0247 de 1957. Diario Oficial n. ${ }^{\circ} 29517$. https://n9.cl/vd3z

Melo, J. (1989) La constitución de 1886. Nueva Historia de Colombia (vol. 3). Planeta.

Ministerio del Interior (s. f.). Origen Ministerio del Interior. Consultado el 4 de mayo de 2020. https://www. mininterior.gov.co/el-ministerio/historia

Ministerio de Justicia. (s. f.) Historia. Consultado el 4 de mayo de 2020. https://www.minjusticia.gov.co/ ministerio/nuestra-entidad/historia

Núñez, R. (1885, 11 de noviembre) Exposición del Presidente de la República al Consejo de Delegados [conferencia]. Consejo Nacional de Delegatarios, Bogotá, Colombia.

Olarieta, J. (2011) La separación de poderes en el constitucionalismo burgués. Nómadas, Critical Journal of Social and Juridical Sciences, 32(4). http://www.redalyc.org/articulo.oa?id=18120706014

Pérez, J. (2018). La independencia del poder judicial en la historia constitucional española. Historia Constitucional, 19, 47-87. https://dialnet.unirioja.es/servlet/articulo?codigo=6536534

Presidencia de la República (1910, 1 de diciembre). Ley 88 de 1910. En desarrollo del Acto Legislativo número 8 de 1910. Diario Oficial n. ${ }^{\circ}$ 01. https://n9.cl/hid03

Presidencia de la República (1947, 17 de enero). Decreto 105 de 1947. Por el cual se reglamenta la Ley 68 de 1945, se organiza el Ministerio de Justicia y se dictan otras disposiciones. Diario Oficial n. ${ }^{\circ} 26339$. https:// n9.cl/4jOfO

Presidencia de la República (1954, 2 de junio). Decreto 1709 de 1954. Por el cual se crea el Fondo Rotatorio Judicial y se dictan otras disposiciones. Diario Oficial n. ${ }^{\circ}$ 28503. https://n9.cl/mikf9

Presidencia de la República (1955, 6 de septiembre). Decreto 2404 de 1955. Por el cual se reglamenta el Decreto número 1709 de 1954, orgánico del Fondo Rotatorio Judicial. Diario Oficial n.o 28863. https://n9.cl/6rit

Presidencia de la Republica (1960, 18 de julio). Decreto 1716 de 1960. Por el cual se reorganiza el Ministerio de Justicia. Diario Oficial n. ${ }^{\circ}$ 30306. https://n9.cl/ut6n

Presidencia de la Republica (1973, 26 de junio). Decreto 1208 de 1973. Por el cual se dictan normas sobre régimen de adquisiciones y suministros con destino a la Rama Jurisdiccional y el Ministerio Público y se reorganiza al Fondo Rotatorio del Ministerio de Justicia. Diario Oficial n. ${ }^{0}$ 33892. https://n9.cl/bnyvt

Presidencia de la Republica (1979, 28 de diciembre). Decreto 3266 de 1979. Consejo Superior de la Adjudicatura. Diario Oficial n. ${ }^{\circ}$ 35436. https://n9.cl/69vl

Presidencia de la Republica (1980, 9 de mayo). Decreto 1064 de 1980. Por el cual se modifica y adiciona el Decreto 3266 de 1979. Diario Oficial n. ${ }^{0}$ 35524. https://n9.cl/vj09d

Presidencia de la Republica (1991) Informe de la sesiones de la Comisión Tercera, correspondiente al 15 de mayo de 1991. Centro de información y sistemas para la preparación de la Asamblea Nacional Constituyente. http://babel.banrepcultural.org/cdm/ref/collection/p1 7054coll28/id/241 
Presidencia de la República (1991, 25 de noviembre). Decreto 2652 de 1991. Por el cual se adoptan medidas administrativas para el funcionamiento del Consejo Superior de la Judicatura. Diario Oficial n. ${ }^{\circ} 40177$. https://n9.cl/41xu3

Presidencia de la República (1992, 30 de diciembre). Decreto 2160 de 1992. Por el cual se fusiona la Dirección General de Prisiones del Ministerio de Justicia con el Fondo Rotatorio del Ministerio de Justicia. Diario Oficial n. ${ }^{\circ}$ 40703. https://www.funcionpublica.gov.co/eva/gestornormativo/norma.php?i $=66507$

Sáenz, E. (1996). La prehistoria del narcotráfico en Colombia. Serie documental: Desde la gran depresión hasta la Revolución Cubana. Innovar, 8, 65-92. https://revistas.unal.edu.co/index.php/ innovar/article/view/19259

Uprimny, R. (1997). Administración de justicia, sistema político y democracia: algunas reflexiones sobre el caso colombiano. En IEPRI (ed.), Justicia y Sistema Político (pp. 67-118). Instituto de Estudios Políticos y Relaciones Internacionales IEPRI; Universidad Nacional; Fundación Friedrich Ebert de Colombia.

Valdés, D. (2004) Los consejos de la judicatura: desarrollo institucional y cambio cultural. En M. Carbonell (coord.) Retos y perspectivas de la procuración de justicia en México (pp. 105-143). Universidad Nacional Autónoma de México.

Vicepresidencia de la República (1894, 27 de noviembre). Decreto 1238 de 1894. En desarrollo de la Ley 11 de 1894, sobre número, nomenclatura y precedencia de los Ministerios del Despacho Ejecutivo. Diario Oficial n. ${ }^{\circ}$ 9663. https://n9.cl/hdtd7

Zubiría, A. (2012). La historia de la Rama Judicial en Colombia. Criterio Jurídico Garantista, 6(3), 154-187. http://dx.doi.org/10.26564/21453381.393 